\title{
ACCOUNT OF A CASE
}

IN WHICH THE

\section{CORPUS CALLOSUM AND FORNIX WERE IMPERFECTLY FORMED,}

AND THE

\section{SEPTUM LUCIDUM AND COMMISSURA MOLLIS WERE ABSENT.}

BY

J. LANGDON H. DOWN, M.D. LoND., ASSISTANT-PHYSICIAN TO, AND LECTURER ON COMPARATIVE ANATOMY AT, THE LONDON HOSPITAL; PHYSICIAN TO THE ASYLUM FOR IDIOTS, EARLSWOOD.

COMMUNICATED BY

T. B. CURLING, Esq., F.R.S.

Received May 3rd,-Read June 25th, 1861.

The medical literature of examples of defective commissures of the brain comprises so few cases, and of these the life-history is so imperfect, that I need no apology in placing the records of another before the members of this Society. The question has often been proposed to me, what relation idiocy bears to these arrests of development. At an early stage of my inquiry into the pathology of idiocy, I was prepared to meet with many cases characterised by the heading of this paper, but on further investigation found that, with the exception of deficient commissura mollis, absence or defect of the larger commissures of the brain 
occurred but seldom. Among fifty brains of idiots which I have dissected, the following is the only example of this nature.

That idiocy frequently depends on defective commissural connection my present experience does not support; but, on the other hand, that the absence of such connection may not occasionally be a cause of this calamity is, I apprehend, a question sub judice.

Mr. Paget, in the twenty-ninth volume of your 'Transactions,' has so ably generalised on the cases at that time on record, that there is little to be done beyond adding to the facts illustrating this interesting subject.

The case to which I beg leave to call your attention, is that of A. B-, a boy aged nine years at the time of his death. He had previously been under my daily observation for two and a half years. He was the first-born of three children; the second, a boy, is also idiotic ; while the third and youngest, a girl, is healthy and intelligent. The respective ages of his father and mother, at the time of his birth, were twentysix and twenty-seven years; there was no consanguinity between them. There is no history of mental disease, or of any such defects as club-foot, hare-lip, cleft palate, \&c., in either branch of the family. The mother's brother died of phthisis, but it was not thought to be owing in any way to constitutional predisposition. The mother, anteriorly to her marriage, had suffered intense pain in the left side, accompanied by hysteria; subsequently to her marriage, and during the pregnancy which speedily followed, there was no diminution, but rather an increase, of these sufferings. The pregnancy was attended by violent vomiting; and the pain in the side becoming more and more insupportable, opiates were largely resorted to for its relief. About this time Sir Benjamin Brodie was consulted, and his written opinion expresses the belief that she was suffering from renal oxalateof-lime calculus. There were no unusual circumstances during parturition.

At five years of age the boy was received into the Asylum for Idiots at Earlswood. He was then a fair and delicate child, 
three feet three inches in height, fifty-three pounds and a half in weight; the shape of his head was oval, the circumference above the eyebrows eighteen inches and five eighths, length between the eyebrows and occipital protuberance eleven inches and three quarters, width of forehead four inches and a half. At this time he could stand alone, but was unable to walk; he was fed with a spoon, as he had no notion of masticating, and it was necessary for his nurse to convey the food to the fauces in order to excite the reflex act of deglutition. He could not speak, and was very spiteful. His habits were dirty, and this was augmented by frequent diarrhœa. When seven years old he was able to walk, though feebly, and was placed in the infant class for training and instruction. At nine, the period of his death, he could walk and run, his spiteful habits had been overcome; he was mild and tractable, and exhibited much fondness for his younger brother. He was timid, and afraid of certain toys; did not play with other children, and found most amusement in looking at a picture scrap-book. He was fond of listening to music; had little or no power of imitation. Although great pains were taken to instruct him, he could scarcely be said to have learned anything. He would in some measure go through simple exercises in drilling at command, but could not be taught to throw a ball with any aim. There was no want of co-ordination in his movements, and no diminution of sensation; his habits had become moderately correct; he was able to feed himself with a spoon, the meat having been previously minced, and with much difficulty he was taught to raise a cup to his mouth. He remembered his father and mother; on seeing any lady in black, the colour usually worn by his mother, he would approach, and after examination would say, "No mamma! no!" which, with the word " $m e$ " when he wanted anything, was the full extent of his powers of utterance. He had no vivacity, and his extreme pallor was remarkable.

His physical health was far from good; he was never long free from either strumous ophthalmia, eruptions at the nasal and oral orifices, thecal abscesses, or diarrhœa; but he had 
never been subject to convulsions or epileptic fits. He died from pneumonia on the right side.

A post-mortem examination was made thirty-three hours after death. The right lung was hepatized throughout, except at its anterior margin. Several of Peyer's glands in the ileum were enlarged and congested. The large intestine extremely congested throughout. The testes had descended into the scrotum, but were small; the pubes was sparsely covered with hair. The other organs were healthy.

The calvarium was of normal thickness, but somewhat unsymmetrical; there were granular patches in the arachnoid on both sides of the longitudinal fissure, and between these and the dura mater slight adhesions. The encephalon weighed two pounds eight ounces avoirdupois ; the cavity of the arachnoid contained about two ounces of straw-coloured serum ; the membranes and sinuses normal. The antero-posterior diameter of the cerebrum was six and a half, its width five and a half inches ; the width of each hemisphere, measured across the anterior lobe, in front of the remnant of the corpus callosum, two and a quarter inches. The anteroposterior diameter of each hemisphere of the cerebellum was two and a quarter, its entire width three and a half inches.

On making sections of the cerebrum and cerebellum, there was nothing noticeable respecting the size, form, arrangement, or colour of the convolutions. On the first removal of the encephalon from the cranium, it was noticed that, on being placed in its natural position, the hemispheres separated to an unusual extent, without bringing into view the great commissure of the brain, but displaying, instead, the velum interpositum. Anterior to the velum, and on the same plane, was exposed, on forcibly separating the hemispheres, a narrow band of medullary structure. A horizontal section of both hemispheres, so as to display the interior of the lateral ventricles, was then made, and the velum interpositum removed. The brain was in no part of its structure deficient in cohesion; the posterior cornu of each of the lateral ventricles was enlarged, and contained 
about half an ounce of straw-coloured serum each. The small hippocampus on each side was rather large; the tænia semicircularis very fully developed. At this stage of the dissection no remnant of the fornix could be discerned; there was positive absence of any septum lucidum. The third ventricle was exposed, but no middle commissure could be discovered; the pineal gland occupied its usual position between the lobes of the corpora quadrigemina, all which structures were of normal size and appearance. At the anterior boundary of the third ventricle there was the before-mentioned medullary band, which was regarded as the representative of the corpus callosum, but occupying a much lower plane than the normal position of the commissure. It presented, both anteriorly and posteriorly, crescentic, thinned margins, and measured at its narrowest part, which was slightly to the left of the mesial line, one third of an inch. A section was then made through both hemispheres on a level with the transverse band. The optic thalami were unusually flattened, and their inner surfaces indicated that the soft commissure had never been present. There was a marked absence of the peduncles of the pineal gland. The third ventricle presented on its floor the usual structures, and at its anterior part could now be seen the anterior pillars of the fornix ascending at slight angles, but widely separated throughout. Beneath the posterior margin of the transverse band they made a sudden bend, and, passing outward and backward over the upper surface of the optic thalami, terminated in the descending cornua of the lateral ventricles as the tæniæ hippocampi, the tæniæ, however, being narrower than usual. The optic commissure at the floor of the third ventricle was strongly marked, and the lamina cinerea interleaved between it and the anterior commissure, where it terminated. The anterior commissure was well defined, and above it an interval of two lines occurred between it and the transverse band. The inner surfaces of the anterior lobes of the cerebrum were separated inferiorly as far as the anterior commissure; and the parts of them into which the knee and reflected portion 
or rostrum of the corpus callosum are usually inserted were covered with convolutions such as are common to other parts of the cerebral surface. The band or rudiment of corpus callosum was situated opposite the widest portion of the corpora striata; its anterior edge being two and one twelfth inches from the anterior margin of the cerebral hemispheres, and its posterior border being four and one twelfth inches from the posterior margin of the hemispheres. It did not exceed one sixteenth of an inch in thickness at any part of it, and its fibres spread out anteriorly and posteriorly on reaching the hemispheres. It will follow from this description that there was no representative of the germ or of the reflexed portion of the corpus callosum; that the body of the fornix, septum lucidum, and its fifth ventricle, and the soft or middle commissure, were entirely absent; and that there existed no communication between the lateral representatives of the fornix; moreover, that these had no connexion with the posterior diverging fibres of the transverse band, and consequently that not even the analogue of a septum lucidum was present.

Mr. Paget, in the twenty-ninth volume of your 'Transactions,' has grouped together with his own case others related by Reil, Mr. Solly, and Mr. Chatto, and has made some important physiological deductions. The case related by him was "not remarkable for any excellence or great defect of mind." In Mr. Solly's, the boy, although "boobyfied," could read, and selected as his favorite reading religious books. Reil's case, a woman, was of dull intellect, but could go errands in the village. Mr. Chatto's patient lived only twelve months.

In comparing the case which has been here detailed with those referred to by Mr. Paget, it would, at first sight, appear to stand opposed to the conclusions at which he arrived, and to support the view that the corpus callosum is necessary to the possession of the average power of the human mind. But this opposition may be only apparent; for it is a circumstance worthy of special regard in instituting a comparison, that while in the three above-named 
examples the soft commissure was present, in the one which I have brought forward it was entirely absent. Moreover, in Mr. Solly's case, the soft commissure was "wide and thick," and in Mr. Paget's it was inordinately large, measuring six tenths of an inch from before backwards, and being also thicker than usual.

How far the presence of extra large, middle commissures compensated for other deficiencies in the former cases, and how far its absence was the cause of the extreme mental deficiency in the present instance, I shall not now discuss. I will only say that my researches hitherto lead me to attach a physiological importance to the soft commissure which previous observers have not recorded. 